EVS26

Los Angeles, California, May 6 - 9, 2012

\title{
Analysis of the Fault Tolerance of a Switched Reluctance Machine with Distributed Inverter
}

\author{
Martin D. Hennen, Matthias Boesing, Rik W. De Doncker \\ Institute for Power Electronics and Electrical Drives, RWTH Aachen University \\ Jaegerstr- 17-19. 52064 Aachen, hennen@gse.rwth-aachen.de
}

\begin{abstract}
This paper analyzes how distributed inverters can further increase the fault tolerance of switched reluctance traction drives. The drive under investigation is an outer-rotor direct-drive switched reluctance machines (SRM) for railway traction. The phases of SRMs are magnetically and to a certain extend electrically decoupled. Hence, in case of a fault inside a phase, the remaining phases can continue operation with reduced power. With the distributed inverter concept at hand, each coil of a phase is excited by its own modular inverter. This increases the redundancy, simplifies integration of machine and inverter, and enables a new degree of freedom regarding the control of the machine. Especially for electric drives used in railway traction or electric vehicles, redundancy avoids all the inconveniences of a standstill in case of a fault, enabling a so-called limp home capability. This paper shows, how open- and short-circuit faults of single coils or modules of the proposed drive influence average torque, torque ripple, and noise and vibration. Therewith, it will be shown that with the SRM and the distributed inverter it is possible to continue operation in case of the analyzed faults.
\end{abstract}

Keywords: electric drive, powertrain, switched reluctance motor, inverter, reliability, limphome

\section{Introduction}

Redundancy can be a key requirement for electric traction drives. Railway traction application require full operation even under partial system failure. In electric vehicles, at least a complete system failure should be avoided and thus a socalled limp home capability is desired for both passenger safety and comfort. In industry applications, the breakdown of a drive can lead to intensive costs and safety issues if for instance the fault stops a production facility or if the drive is responsible for ventilation. In aviation, the loss of a fuel pump or a generator in a plane risks a fatal crash. Therefore, most of the safety critical components in planes are highly redundant. The strong demand for reliability can often outweigh the additional costs, necessary to make the drive more reliable and safe.

With switched reluctance machines (SRM) this increased reliability comes at moderate extra cost making it attractive also for cost sensitve applica- tions, for example in electric vehicles. A further important characteristic of the machine is that it does not use expensive magnetic materials nor copper windings on the rotor. It's simple design leads to a low cost machine, compared to other machine types. Furthermore, the SRM is inherent fault tolerant, due to the magnetic and electric independence of the machines phases.

The extensive research for the so called More Electric Aircraft, replacing hydraulic, pneumatic and mechanical transfer systems with electric SR drives [1, 2, 3], shows that SRMs are in focus of such highly critical applications due to their fault tolerance. The SRM is furthermore seen as promising solution for future starter-generator systems or fuel pumps in aircraft engines. In [4], a starter-generator for aircraft engines is shown, based on a three-phase SRM. Three advantages are stated: First, the physical and electromagnetic isolation of the phases, reducing the possibility of phase-to-phase faults and allowing isolation of the faulted phase. Second, the lack of 
Table 1: Specifications of the designed SRM

\begin{tabular}{cc}
\hline Stator/rotor teeth & $20 / 16$ \\
Phase number & 5 \\
Outer rotor radius & $320 \mathrm{~mm}$ \\
Inner rotor radius & $259 \mathrm{~mm}$ \\
Outer stator radius & $257.5 \mathrm{~mm}$ \\
Inner stator radius & $150 \mathrm{~mm}$ \\
Stack length & $150 \mathrm{~mm}$ \\
Airgap & $1.5 \mathrm{~mm}$ \\
Number of turns per coil & 160 \\
Nominal torque & $1800 \mathrm{Nm}$ \\
Nominal power & $66 \mathrm{~kW}$ \\
Maximum speed & $750 \mathrm{rpm}$ \\
Copper fill factor & $60 \%$
\end{tabular}

an excitation source on the rotor, not leading to a generated power in a faulted phase; and last, the power converter topology, which has the phase coil in series with the power devices, preventing a shoot-through fault mode in case of a fault, as it is the case for the inverters of rotating field machines. Regarding the first advantage, a similar behavior is possible with permanent magnet synchronous machines (PMSM) using concentrated coils. However, the second and third advantages increase the fault tolerance of SRM drives compared to a PMSM drive without any additional costs. These benefits are also of interest for electrical drives in railway and electric vehicles. The low-cost construction and the high inherent redundancy of SRMs illustrate that the SRM should be part of the research for new possible drive concepts.

In this paper, the influence of different faults in the distributed inverter concept for SRMs, introduced in [5], is analyzed. The distributed inverter concept uses one inverter module for each coil of the machine. Hence, not only the phases but also single coils of one phase are electrically decoupled. This increases the redundancy of the machine, because the failure of one module does not lead to the failure of the complete phase. However, the influence of faults in single modules on torque, vibration and noise has to be investigated. All results are based on a five-phase outer-rotor switched reluctance direct drive for railway traction application, as presented in [5]. The specifications of the machine are given in Table 1. The number of stator teeth corresponds to the number of necessary inverter modules. Figure 1 shows the prototype of the machine and the inverter.

In Section 2 simulation results of the influence of faults of single modules on average torque, torque ripple, net radial force and the spectral composition of the excited forces are shown. The results show, that the drive can continue operation after a fault has occurred. To proof the simulation results and therewith the developed simulation model, Section 3 illustrates experimental results measured at the test bench.



Figure 1: Prototype of inverter and machine

\section{Simulation of Faults}

As described in Section 1, with the distributed inverter single poles of one phase can fail independently. Therefore, the simulation model needs to model each pole separately. In general, mutual coupling between the phases of an SRM can be neglected if the saturation of the rotor and stator yoke is neglected and the machine is excited symmetrically with an even number of poles, as shown for example in $[6,7,8]$. Mutual coupling describes the influence of an active phase on other phases. Provided that mutual coupling is neglected, the phases of the SRM are magnetically independent.

With the distributed inverter at hand, an asymmetric excitation within the four poles of one phase is possible. For the case that one module of a phase fails, Figure 2 shows the results of a FEM simulation with three out of four poles of one phase active. In this case, a flux linkage is induced in all other teeth of the machine. Therefore, the simulation model needs to regard mutual coupling between all teeth of the machine.

Two different solutions to model the asymmetric flux linkages and faults of the given machine have been regarded. The first is to embed an FEM of the machine in a dynamic simulation environment, as for example MATLAB/Simulink. There, in each time step the FEM is solved and the results are returned to the simulation model. In $[9,10]$, an example of a dual-channel 12/14 SRM is shown simulated with a coupled MATLAB/Simulink - Flux 2D model. The main drawback of this method is the high computation time, which is necessary to run the simulation. The second solution is to build a network of lumped reluctances and flux sources, representing the machine. Compared to the coupled FEM - MATLAB/Simulink simulation, the network has to be recursively solved in each time 


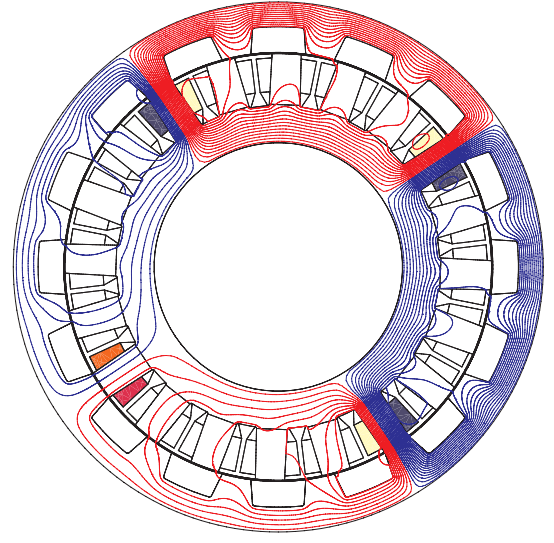

Figure 2: Results of FEM simulation for three out of four poles of one phase active

step, however, the computation is significantly reduced because the network consists of less than 100 elements for the complete machine. Using this network, mutual coupling and saturation effects are taken into account and all flux linkages, currents and forces affecting each tooth can easily be determined. Details on the developed simulation model can be found in [11].

The simulation model of the drive also includes a direct torque control, using Predictive PWM-based Direct Instantaneous Torque Control (PWM-DITC), as proposed in [12]. PWMDITC is a non-linear predictive torque controller using pulse-width modulation. The instantaneous torque is estimated using the current and the position of the phase [13]. The reference torque is then shared among the active poles and the torque per pole is used to calculate a duty cycle for each module to reach the demanded torque. With the developed torque sharing algorithm, as described in [14], it is possible to compensate for faults in single modules. For this compensation, a prerequisite is that the controller is aware of the failing modules. How failures in SRMs can be detected is shown for example in [15], [16] or [17]. Also, the compensation is only possible within certain current limits, because the load of the remaining models is increased.

\subsection{Influence of Open-Circuit-Faults}

Switched reluctance machines are inherent fault tolerant. For the given prototype, without any compensation by the remaining active modules, the overall torque is reduced by approximately one twentieth of the reference torque for each failing module, as has been shown in [5]. If all four modules of a phase fail, the machine torque is reduced by $1 / N_{\mathrm{ph}}$, hence, by $20 \%$ of the reference torque. The torque ripple increases approximately by $25 \%-30 \%$ with each failing module. In the following, the developed torque sharing algorithm is used to compensate for the missing torque. The results can be compared to the above mentioned effects of a failure without compensation. Figure 3 illustrates the currents and the to- tal torque for an operating point of $1000 \mathrm{Nm}$ and $200 \mathrm{rpm}$. Shown are the simulation results of no fault (1111), the fault of one module (0111), the fault of two opposite modules (0101), the fault of two neighboring modules (0011) and the fault of all modules (0000) of phase 1. In Figure 3(a), (b) and (c) the currents of one active module for the out-going phase 5 , the faulty phase 1 and the in-coming phase 2 are depicted.

If one module in phase 1 fails, the currents of the out-going phase 5 and of the remaining modules in phase 1 are increased. Consequently, the torque ripple, illustrated in Figure $3(\mathrm{~d})$, can be compensated at this operating point. If another module fails, e.g. opposite to the previous fault (0101), the currents in phase 5 and 1 are increased further. The resulting ripple is approx. $12 \%$. This value is significantly lower compared to the approximate $60 \%$ in the case 0101 with no fault compensation. Moreover, it can be seen in Figure 3(d) that the case 0011 has a lower torque ripple compared to 0101 .

If a complete phase fails (0000), the controller tries to compensate for the fault by increasing the turn-on time of phase 5, shown in Figure 3(a). The current of phase 1 in Figure 3(b) is zero. Nevertheless, the torque ripple reaches $80 \%$, due to the loss of the 4 modules. Still, this is significantly lower compared to no fault compensation. To investigate the influence of different faults on the torque ripple over the entire operating area, the developed MATLAB/Simulink model has been automated to simulate different faults and different operating points. With increasing number of failing modules the torque ripple is increased, especially in the higher torque range in the low speed area. In the developed simulation model, the current of the modules is limited to $80 \mathrm{~A}$. Therefore, the controller cannot compensate for the torque ripple with the remaining modules at higher torque commands. In the area of $0-100 \mathrm{rpm}$ and torque levels above $800 \mathrm{Nm}$, the controller additionally does not compensate well for the missing torque of the modules in case of faults. In this area, the turn-on and turn-off angles of the control have to be adapted for each phase separately in case of a fault, to guarantee a smooth torque, as is the case at $200 \mathrm{rpm}$.

If Figure 4(b) is compared with Figure 4(a), it can be seen that the lines of constant torque ripple move to lower speeds. For instance, in Figure $4(\mathrm{~b})$ the $10 \%$ line (labeled with 0.1 ) starts at approximately $300 \mathrm{rpm}$, whereas in case of no fault, the line starts at $350 \mathrm{rpm}$. The line of $20 \%$ torque ripple is shifted to $350 \mathrm{rpm}$ in the same manner. Below $300 \mathrm{rpm}$, the torque ripple due to the one failing module can completely be compensated. The maximum ripple at maximum speed is increased approximately by $20 \%$ up to $60 \%$ torque ripple.

The difference between the fault 0011 and 0101 in Figure 4 (c) and (d) is a notable result. The fault 0101 has approximately $10 \%$ higher torque ripple, throughout the operating area. To understand why 0101 is worse regarding torque ripple, one has to remember the direction of the flux linkage in the coils. In one phase, the direction is 


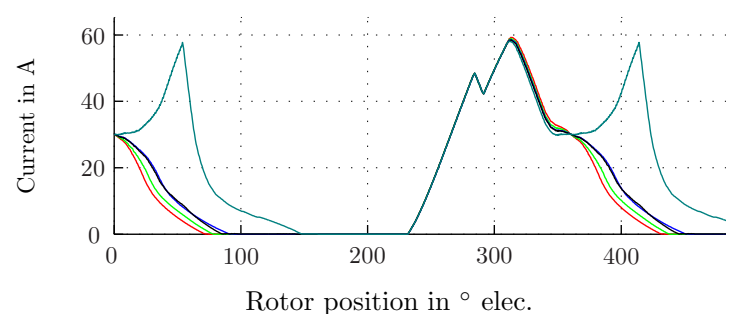

(a) Current of one active module of the out-going phase 5

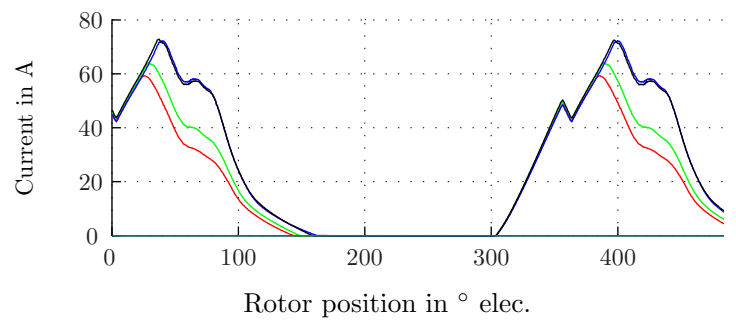

(b) Current of one active module of phase 1 (faulty phase)

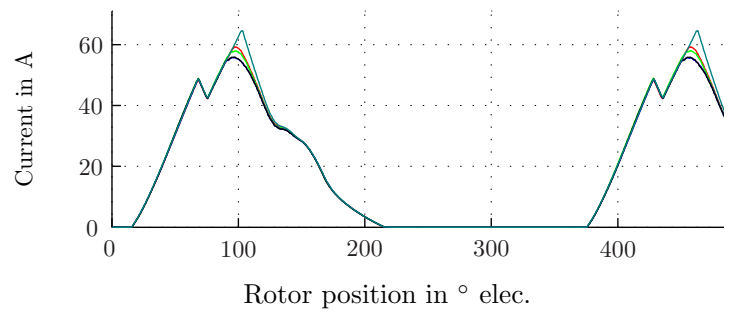

(c) Current of one active module of the in-coming phase 2

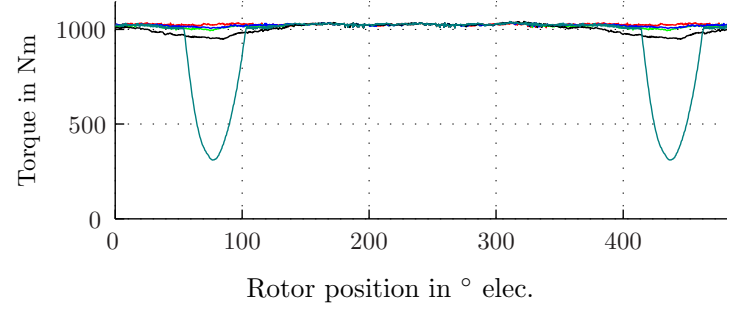

(d) Total torque

$-1111-0111-0011-0101-0000$

Figure 3: Simulation results for different faults at $1000 \mathrm{Nm}$ and $200 \mathrm{rpm}$

always alternated from pole to pole. This means that in the 0101 case, both coils have a positive flux linkage direction, thereby leading to a high amount of induced flux linkage in other teeth, as shown in Figure 5(a). In the 0011 case, one coil has a positive and one coil a negative flux linkage direction. Therefore, the two flux linkages compensate each other, and hence almost no flux is induced in the other stator teeth, as illustrated in Figure 5(b). The same behavior could be realized for the case 0101 by reversing the direction of the flux linkage of one pole. However, this would require additional switches, which is not an alternative due to the increased costs of the inverter.

This can additionally be shown, if the module currents and the induced flux linkages $\Psi_{\mathrm{i}}$ in each

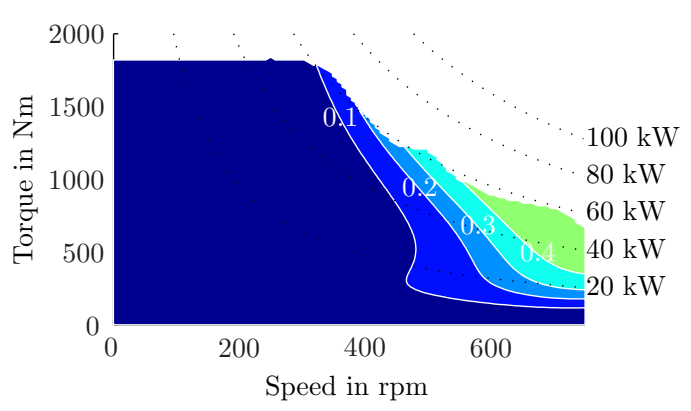

(a) no fault (1111)

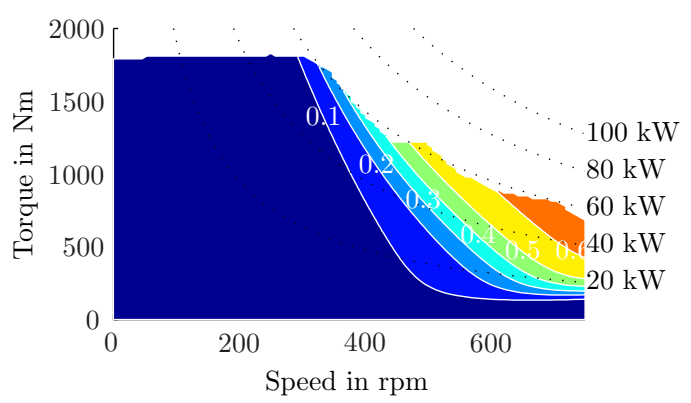

(b) one fault (0111)

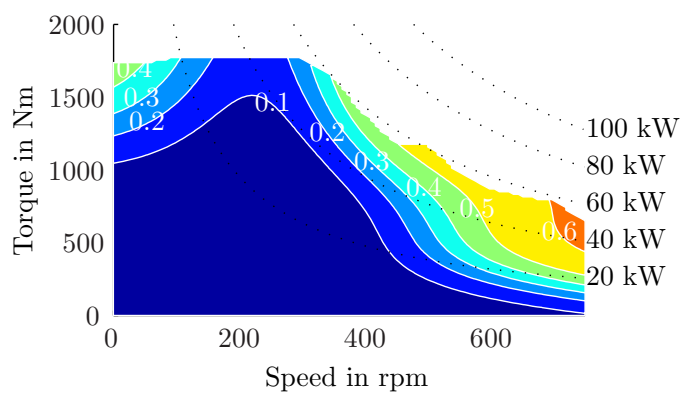

(c) two neighb. faults (0011)

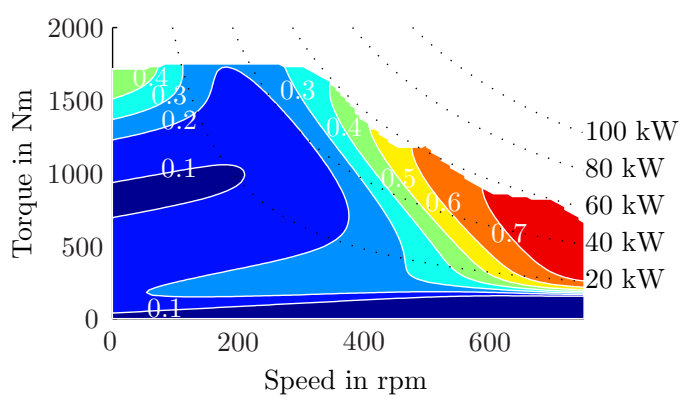

(d) two oppos. faults (0101)

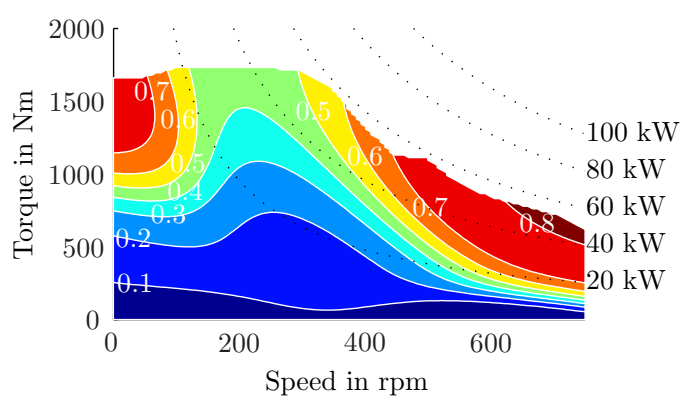

(e) three faults (0001)

Figure 4: Simulated torque ripple for different faults 


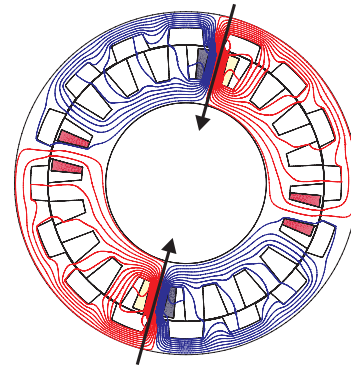

(a) One phase - two opposite modules on (0101)

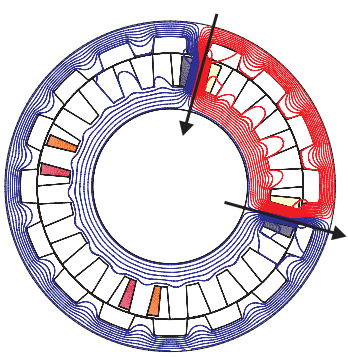

(b) One phase - two neighboring modules on (0011)

Figure 5: Comparison of flux linkage distribution for two faulty modules - rotor position: $132^{\circ}$ elec., $I$ : 50 AT

tooth are depicted for the two faults (Figure 6) The currents of the active modules of the faulted phase (green) are almost identical, as shown in Figure 6 (a) and (b). However, the currents of the other phases are influenced strongly in case of the fault 0101 due to the induced flux linkage in other teeth, as illustrated in Figure 6(a). Figure 6(c) and (d) illustrates the induced flux linkage for the two faults. In the fault case 0101, the induced flux linkage in other teeth reaches levels of up to $0.4 \mathrm{Vs}$, which is approximately $30 \%$ of the peak flux linkage of one tooth. The induced fluxes in the two faulty teeth of the first phase are highlighted in Figure 6(c). In Figure 6(d), it is shown that for the fault 0011 the induced flux linkage is almost zero, as is expected. The shape of the induced flux linkage in Figure 6(c) is typical for the developed drive.

\subsection{Influence of Short-Circuit Faults}

This section analyzes the different short-circuit faults of a coil on a system level. Thereby, different numbers of failing modules are considered. As presented for open-circuit faults, a flux is induced in almost all stator teeth in case of an asymmetric excitation within one phase. Consequently, this flux induces a current in a coil, if the coil is short-circuited. Several different operating points have been simulated, to give an impression of the amplitude and the influence of the induced current.

For the machine and the machine model, a shortcircuit is equal to a zero input voltage at the terminal connections. However, in contrast to normal operation, negative phase currents are physically possible. In normal operation negative current is blocked by the diodes of the inverter. The sign of the induced current depends on the sign of the slope of the induced flux linkage (1).

$$
R i(t)=0-\frac{\mathrm{d} \Psi}{\mathrm{d} t}(t)
$$

The sign of the current is defined positive in each module if a positive voltage is applied. This is important because in the machine the direction

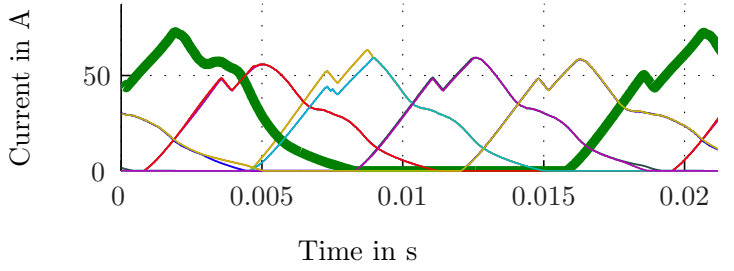

(a) 0101 - module currents

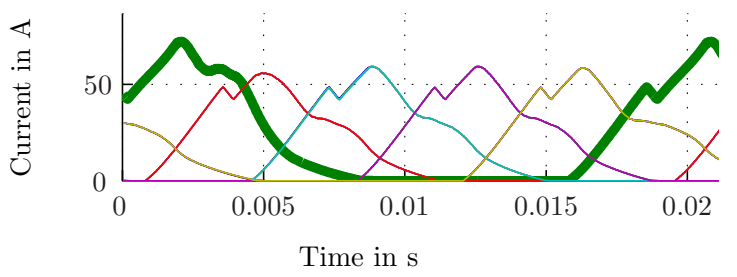

(b) 0011 - module currents

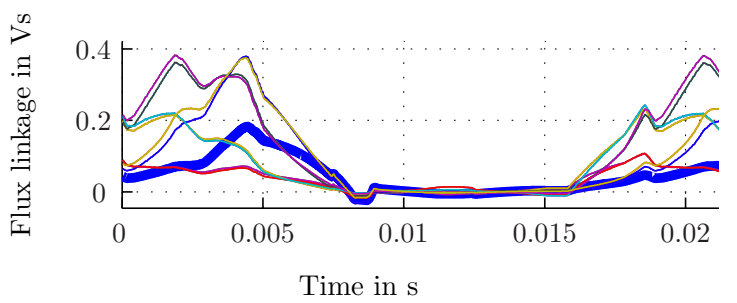

(c) 0101 - induced flux linkage

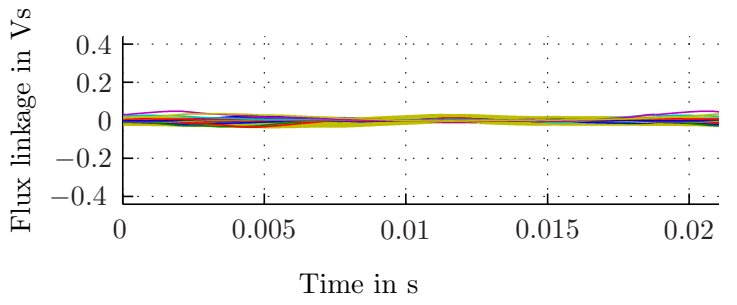

(d) 0011 - induced flux linkage

Figure 6: Simulated induced flux linkage for all teeth at $1000 \mathrm{Nm}$ and $200 \mathrm{rpm}$

of the flux linkage is alternated for every second module within a phase by switching the terminals of the coil. Therefore, the real current direction changes from module to module. In case of a short-circuit fault in one coil the current in that coil, induced by the remaining modules of the same phase, is always negative. Only the other phases can induce flux in the opposite direction, thereby, leading to a positive induced current.

The induced current depends on the operating torque and speed of the machine. It increases with speed due to the increased overlap the phase and the higher back e.m.f.. In addition, a higher torque requires a higher flux in the machine and therefore, more flux is induced in the shortcircuited coil. As an example, a healthy and a short-circuit current of two modules of one phase for the fault case 2121 ( 1 = healthy, $2=$ short circuit) at 200 to $600 \mathrm{rpm}$ and $600 \mathrm{Nm}$ are shown in Figure 7(a) and (b), respectively. In addition, the total torque produced by all phases is depicted in Figure 7(c). Figure 7(b) illustrates, how the induced current increases with speed. At low 


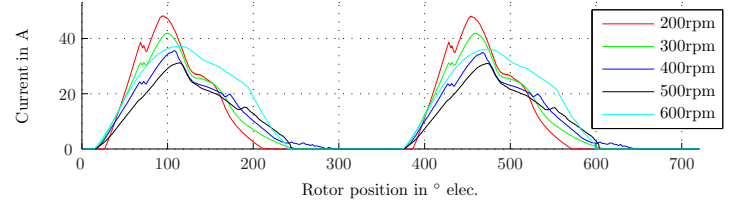

(a) Excited current in an active module of phase 1



(b) Short-circuit current in a faulty module of phase 1

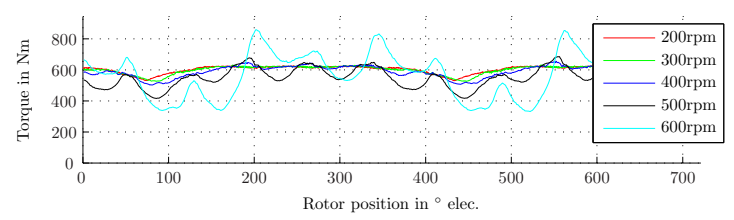

(c) Total torque

Figure 7: Simulated module currents and total torque - two opposite short-circuit faults (2121) at $600 \mathrm{Nm}$, $200 \mathrm{rpm}-600 \mathrm{rpm}$

speed, the induced current is mainly negative. Consequently, the current is almost exclusively induced by the modules of the same phase. However, by increasing the speed, the overlap of the phases increases due to the earlier turn-on of the phases, and hence, more positive current is induced. The maximum current peak, reached in this example at $600 \mathrm{rpm}$, is approximately $7 \mathrm{~A}$. The influence of the induced current on the total torque is small. The total torque in Figure 7(c) is similar to the torque of a 0101 open-circuit fault. The influence of the induced currents on the operation of the drive is negligible. The maximum simulated rms value of a short-circuit current throughout the operating range of the machine is approximately one fifth of the maximum allowed coil current $\left(8 \mathrm{~A}_{\mathrm{rms}}\right)$. Therefore, the induced currents are far below the allowed current density of the coil. The induced rms currents over the entire operating area in a shorted module in the fault case 2121 are illustrated in Figure 8. In addition, the resulting torque ripple is similar to the open-circuit fault cases due to the small influence of the induced current in the faulted coils. Consequently, short-circuit faults of the coils have a similar effect on the operation of the proposed drive as open-circuit faults and furthermore, the induced current does not lead to an overheating of the faulty coils. Ultimately, the machine can continue operation.

\subsection{Unbalanced Magnetic Pull}

Figure 9 shows the cross section and the forces of the machine for 1111, 0111, 0011 and 0101 at a rotor position of $82.4^{\circ}$ elec. degree at $1000 \mathrm{Nm}$ and $200 \mathrm{rpm}$. At this rotor position in this ex-



Figure 8: Induced current in a short-circuited coil over the operating area (2121)

ample, the faulty phase has its maximum radial force. The resulting net radial force, the socalled magnetic pull $F_{\mathrm{mp}}$, is shown as a vector in the center of the machine. The amplitude depends on the fault and is $4098 \mathrm{~N}$ for the case 0111 and $7682 \mathrm{~N}$ for the case 0011 . For the cases 1111 and 0101 the radial forces are symmetric and therefore, add up to zero. At nominal torque $(1800 \mathrm{Nm})$, the amplitude of $F_{\mathrm{mp}}$ rises up to $6612 \mathrm{~N}$ in case of 0111 and $11248 \mathrm{~N}$ in case of 0011. Furthermore, this force is excited periodically every electrical period; hence, the frequency of the unbalanced magnetic pull is the multiplication of speed and the number of rotor teeth $\left(n \cdot N_{\mathrm{r}}\right)$.


(a) No fault (1111), $F_{\mathrm{mp}}=$ (b) One fault $\quad$ (0111), $0 \mathrm{~N}$ $F_{\mathrm{mp}}=4098 \mathrm{~N}$
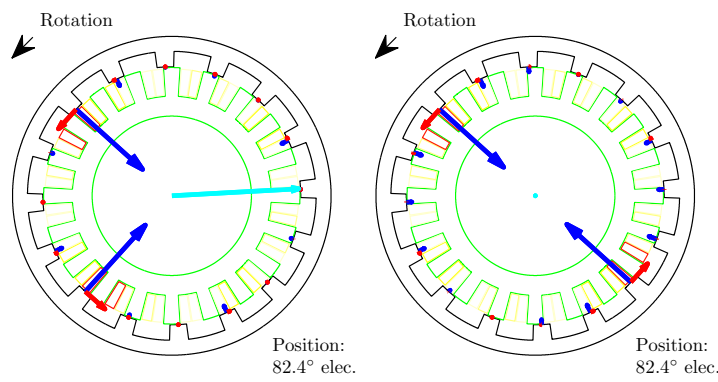

(c) Two neighboring faults (d) Two opposite faults (0011), $F_{\mathrm{mp}}=7682 \mathrm{~N}$

(0101), $F_{\mathrm{mp}}=0 \mathrm{~N}$

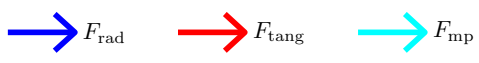

Figure 9: Excited forces on rotor for different faults at $200 \mathrm{rpm}$ and $1000 \mathrm{Nm}$ 
The amplitude of $F_{\mathrm{mp}}$ is small, compared to the weight of the later application (e.g. $18 \mathrm{t}$ vehicle with four wheels). However, the increase of stress on the bearings reduces the lifetime of the bearings and increases vibration and noise.

\subsection{Spectral Composition of Excited Forces}

To analyze the excited vibration modes and their excited noise level in detail, a spectral decomposition of the radial forces on the stator teeth is carried out. The forces are obtained using the developed MATLAB/Simulink model of the drive. The calculation comprises the following four steps:

1. Calculate the time dependency of the forces $F_{\mathrm{m}}(\mathrm{n})$ for each excited force shape $(\mathrm{m} \in$ $[0 ; 4]$ ) from the radial forces of the 20 stator teeth $F_{\mathrm{t}}(\mathrm{n})$ for each time step n with a spatial Fourier analysis.

In other words, the 20 simulated stator tooth forces for one electrical period are used to perform a spatial decomposition of the forces, as shown in [18]. The spatial decomposition is basically a Fourier synthesis of the amplitude of the 20 forces on the teeth over the circumference of the machine.

2. Determine the discrete spectral composition $F_{\mathrm{m}}(\mathrm{k})$ of the time dependent excited force shapes $F_{\mathrm{m}}(\mathrm{n})$ with a second Fourier synthesis.

With the identified vector of the force shapes $F_{\mathrm{m}}($ n), the spectral composition $F_{\mathrm{m}}(\mathrm{k})$ and hence, the frequency components $\mathrm{k}$ of each force shape, are identified.

3. Weighting the spectra $F_{\mathrm{m}}(\mathrm{k})$ with a second order system.

It is possible to find a transfer function that describes the acceleration of the rotor surface as a reaction on the force shapes on the rotor teeth. These transfer functions can be derived, for instance, with a harmonic analysis [19]. In this paper, a second order system is used to approximate these functions. A function based on the measured eigenfrequencies $\omega_{\mathrm{m}}$ of the machine is built for each mode $((2), \mathrm{m} \in[0 ; 4])$.

$$
G_{\mathrm{m}}(\omega)=\frac{K}{\left(j \frac{\omega}{\omega_{\mathrm{m}}}\right)^{2}+2 \mathrm{j} d \frac{\omega}{\omega_{\mathrm{n}}}+1} \cdot \mathrm{j} \frac{\omega}{\omega_{\mathrm{m}}}
$$

4. Cumulate the weighted frequency components $F_{\mathrm{m}}^{\mathrm{w}}(\mathrm{k})$ to gain the total signal energy of the mode

The estimated transfer functions are used to weight the corresponding force shape spectra $F_{\mathrm{m}}(\mathrm{k})$ The resulting force spectra $F_{\mathrm{m}}^{\mathrm{W}}(\mathrm{k})$ are used to calculate the corresponding signal energy of each mode, as shown in (3).

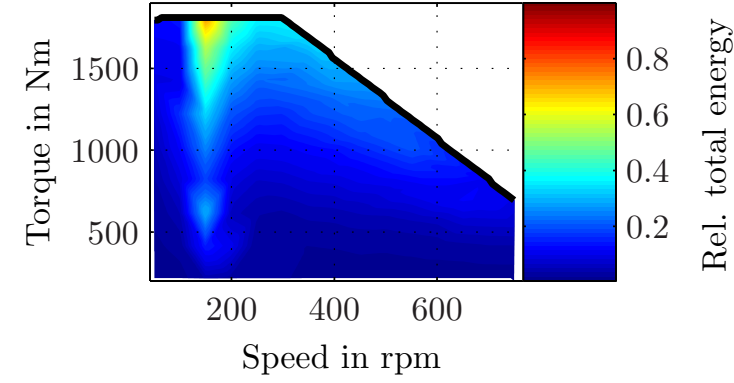

Figure 10: Excitation of mode 1 in case one module fails (0111), unbalanced magnetic pull

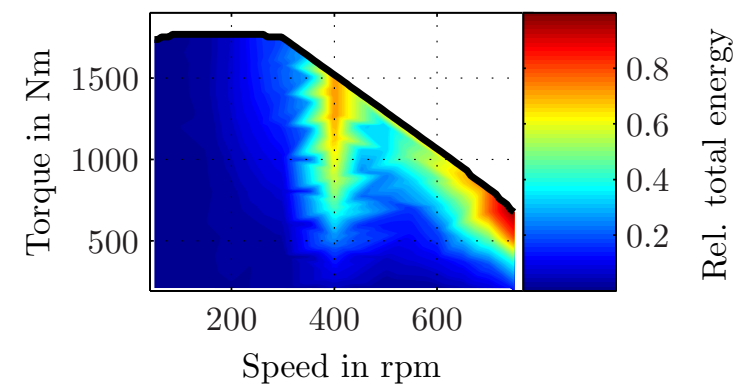

Figure 11: Excitation of mode 2 in case one module fails (0101)

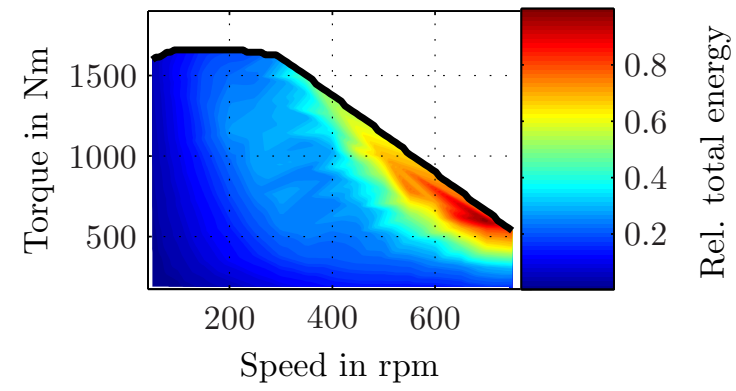

Figure 12: Excitation of mode 0 in case one module fails (0000)

The signal energy is the accumulation of the squared absolute values of $F_{\mathrm{m}}^{\mathrm{w}}(\mathrm{k})$ divided by the number of $L$ components

$$
E_{\mathrm{m}}=\frac{1}{L} \sum_{k=1}^{L}\left|F_{\mathrm{m}}^{\mathrm{w}}(\mathrm{k})\right|^{2}
$$

The calculation of the total energy of the mode is repeated for the complete operating area of the machine and different faults. The results are characteristics of the machine, showing the strength of the excitation of the modes over the entire operating area.

These characteristics help to understand what happens to the drive after a fault and how the controller can react to prevent a strong increase of vibration. As a first example it is supposed that one module fails (0111). Due to the asymmetric excitation of the machine, this fault will lead to an increased excitation of modes 1 , as has 
been shown in [5]. Using the simulated characteristic in Figure 10 it can be seen at what speed of the machine the excitation of mode 1 is critical. For the given machine, the fundamental electric frequency hits the eigenfrequency of mode 1 $(43 \mathrm{~Hz})$ at around $160 \mathrm{rpm}$. Consequently, if at low speeds one module fails, the controller can reduce the excitation of mode 1 by turning-off the opposite module and thereby restoring symmetric operation.

In the symmetric case 0101 mode 1 is not excited and the machine can continue operation without a significant increase of vibration. However, in case two opposite modules are turnedoff, the excitation of mode 2 is increased. The characteristic in Figure 11 illustrates that around $400 \mathrm{rpm}$ the excitation of mode 2 has its maximum. Therefore, to prevent a strong excitation of mode 2, the controller can turn-off the complete phase (0000) in this speed range. This will prevent the excitation of mode 1,2 and 3.

Having turned-off the complete phase, the simulation results in Figure 12 show that if the machine is accelerated to approximately $600 \mathrm{rpm}$, the excitation of mode 0 is increased compared to no fault. In this case, it is possible to turnon the faulty phase again (0111), because in this speed range neither the excitation of mode 1 nor mode 2 is critical.

Thess examples illustrates that it is possible to reduce the vibration after a fault by turning on or off other modules of the machine depending on the operating point. This allows to continue operation after a fault, without at significant increase of vibration, however, with an influence of the maximum possible torque, depending on the overload capability of the remaining modules.

\section{Experimental Results}

In the following sections results of open- and short-circuit faults and run-up tests are shown. The results have been achieved with the prototype of the outer-rotor SRM and the integrated distributed inverter. To measure currents and torque, the internal variables of the control DSP are displayed online on a scope with the help of four digital-to-analog converters. Thereby, the measured currents of modules, the estimated torque of the phases and the total torque can be viewed during operation of the machine. The variables are updated with the $10 \mathrm{kHz}$ sample rate of the PWM. In addition, the torque is measured with a torque transducer mounted to the shaft of the machine. This allows validating the estimated torque with the real measured torque, however, the bandwidth of the transducer is too low to show the torque ripple of the machine, hence, in the following, the estimated torque is used to identify the resulting torque ripple. The tests have shown that the estimated torque is in good agreement with the measured torque of the transducer regarding the average value. Therefore, it is valid to examine the influence of different faults using the estimated torque. Moreover, acceleration sensors have been mounted to the rotor of the machine, to measure the resulting
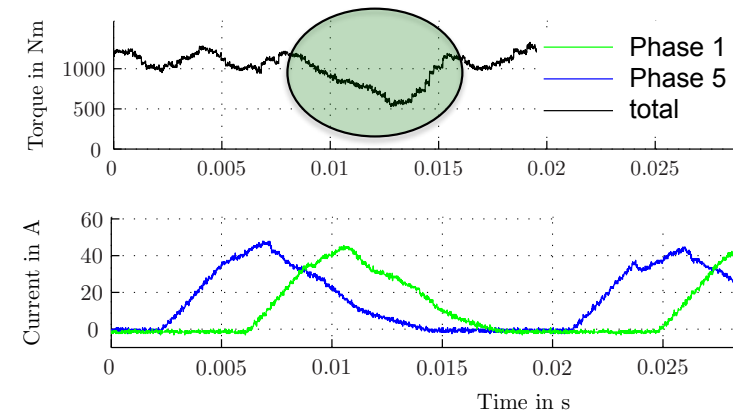

Figure 13: Measured torque and currents with no compensation - two faults (0101) at $200 \mathrm{rpm}$ and $1000 \mathrm{Nm}$
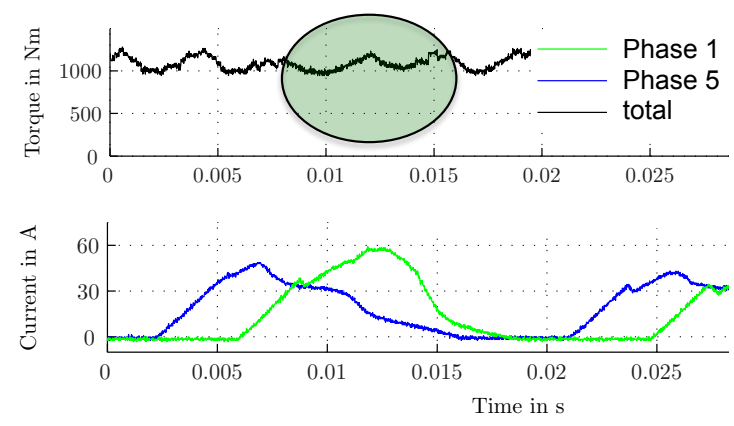

Figure 14: Measured torque and currents with compensation - two faults (0101) at $200 \mathrm{rpm}$ and $1000 \mathrm{Nm}$

vibrations. The signals of these sensors are transmitted to a computer by a telemetry unit, which is fixed at the rotating rotor of the drive. The frequency spectrum of the vibration signals is used to verify the results from the spectral analysis of different faults.

\subsection{Open-Cicruit faults}

The proposed torque-sharing algorithm is used to compensate for the missing torque of the faulty modules, as has been explained in Section 2. To show the influence of the compensation, Figure 13 and Figure 14 show the measured torque and the phase currents of phase 1 and phase 5 at an operating point of $200 \mathrm{rpm}$ and $1000 \mathrm{Nm}$. It can be seen in Figure 14 that the currents of the remaining modules of phase 1 are increased to produce more torque. Consequently, the torque dip in Figure 13 is compensated.

\subsection{Short-Cicruit faults}

In Section 2.2 it has been illustrated that the effects of a short-circuit are marginal, due to the fact, that the induced current in the shorted phase is far below the allowed maximum phase current. In addition, it has been shown that the influence on torque ripple and vibrations is similar in case of a short- or open-circuited coil. In Figure 15(a), two currents of an active module in phase 1 and 


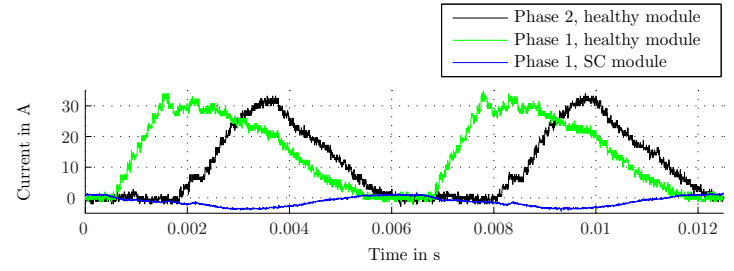

(a) Currents of one healthy module of phase 1 and 2 and a SC module phase 1

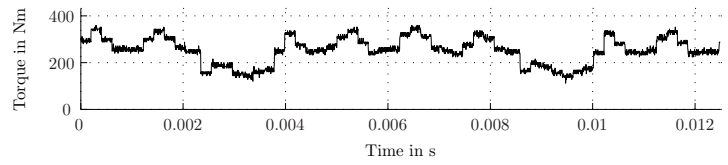

(b) Total torque

Figure 15: Measured current and torque - short circuit of two coils (2121) at $300 \mathrm{Nm}, 600 \mathrm{rpm}$

2 and the measured short-circuit current in one coil of phase 1 are shown. The short-circuit current has been measured with an additional current transducer because the current does not pass the current sensor of the module. As operating point, $600 \mathrm{rpm}$ and $300 \mathrm{Nm}$ is chosen. In this case, two opposite modules are short-circuited (2121). Thereby, the rms value of the induced current in Figure 15(a) is approximately $1.5 \mathrm{~A}$, which matches the simulation results illustrated in Figure 8.

\subsection{Run-Up Tests}

Run-up tests have been performed to investigate the influence of faults over the speed range of the machine and therewith, to verify the spectral decomposition of the simulated forces. The machine is accelerated from standstill to $600 \mathrm{rpm}$ at no load and $200 \mathrm{Nm}$ reference torque.

The measured speed and torque during the runup for no faults (1111) is shown in Figure 16. In Figure 16(b), it can be seen that the torque is almost constant, although, the torque ripple increases towards higher speeds. This is predictable, since the machine operates more and more in single pulse mode.

During the run-up tests, signals from the acceleration sensors mounted on the rotor of the machine have been measured. The result for no fault (1111) is illustrated in Figure 17. In the figure, the two main frequency components of mode 0 and mode 4 can be identified at $2412 \mathrm{~Hz}$ and $1077 \mathrm{~Hz}$.

In addition, during the run-up of the machine, the increasing fundamental electric frequency and its multiples can be seen, which are the ascending lines proportional to speed. In [19], it is shown how the harmonic content of an SRM can be identified. Depending on the topology of the machine, certain harmonics of the fundamental electric frequency are boosted while others are canceled out, due to the spatial and time shift of the phases. In case a multiple of the fundamental frequency hits the eigenfrequency of a mode, the ex-

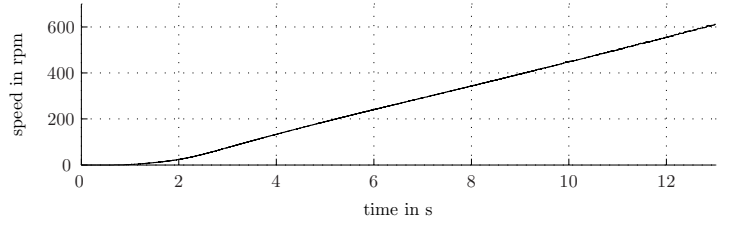

(a) Speed of the machine

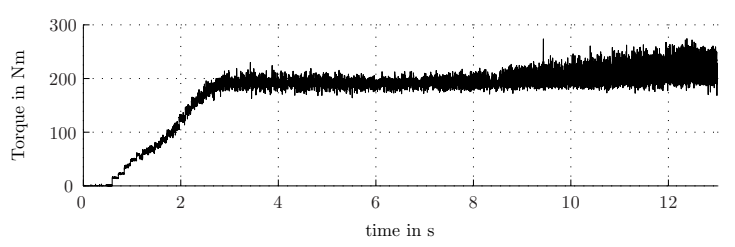

(b) Total torque

Figure 16: Measured speed and torque during run-up - no fault (1111) at no load

citation of the corresponding mode is increased.

In Figure 18, the measured results of the run-up test are illustrated for one faulty module (0111). This asymmetric excitation leads to several resonances below $1000 \mathrm{~Hz}$. The additional excited frequencies are $43 \mathrm{~Hz}$ (mode 1 ), $215 \mathrm{~Hz}$ (mode 2) and $625 \mathrm{~Hz}$ (mode 3). The strongest excitation of mode 1 is at approximately $4.5 \mathrm{~s}$. At this point, the machine reaches the speed of $160 \mathrm{rpm}$. Therefore, the fundamental electric frequency is equal to the eigenfrequency of mode 1 . Beyond this speed, the excitation of mode 1 is reduced. These results proof what has been illustrated in 10.

As has been depicted in Section 2.4, at low speeds the fault of one module and therewith the excitation of mode 1 can be reduced by turningoff the module opposite to the fault, restoring a symmetric operation. The run-up test in Figure 19 illustrates the results for 0101 . The figure shows that over the complete speed range, mode 1 is not excited, as has been expected.

However, the mode 2 excitation is increased significantly towards $400 \mathrm{rpm}$, due to the two-pole excitation of one phase. This has also been illustrated in Figure 11. To reduce vibration at higher speeds, it is either possible to turn-off the complete phase, or to turn-on the module opposite the faulty module again. In Figure 20, the complete phase is turned-off $(0000)$. Thereby, the excitation of modes 1 and 2 is almost completely avoided.

The measured results prove that the simulated vibrations, the excited modes over the speed range and the occurring multiples of the fundamental electric frequency, match the results measured at the test-bench well for all analyzed faults. Therefore, it can be concluded that the developed model of the machine and the spectral decomposition of the radial forces in Section 2.4 can be used to predict the behavior of the drive in case of different faults. This allows, for instance, developing further fault tolerant control strategies by using the introduced simulation tools. 


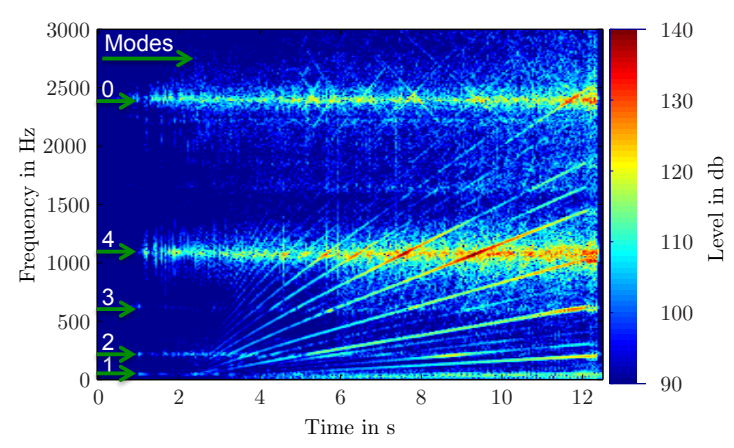

Figure 17: Measured level of acceleration during runup - no fault (1111) at no load

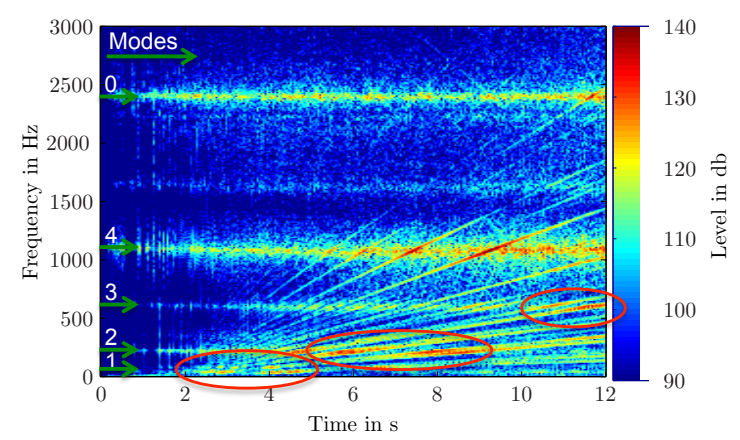

Figure 18: Measured level of acceleration during runup - one fault (0111) at no load

\section{Conclusion}

It is shown how distributed inverters can be applied to increase the fault tolerance of switched reluctance drives. The simulated and measured results show that it is possible to compensate for the torque loss and torque ripple in case of faults of single modules. If the controller detects the fault, a simple fault tolerant control strategy can be applied which, first, turns off additional modules to reduce the excitation of certain eigenfrequencies and, second, increases the currents in the remaining active modules. For the given machine, in case one complete phase fails, the available torque with fault tolerant control is reduced by $10 \%$ compared to no fault. This is half of the reduction if no fault tolerant control is applied. To determine the maximum available torque, a current limit has been set for each module to prevent thermal damages. It is obvious that this limit strongly influences the maximum available torque after a fault.

Due to the lack of an excitation source on the rotor of the SRM, the short-circuit of single coils during operation of the drive is not critical. It has been illustrated that the induced current in the coil is far below the nominal current of the coil and can be neglected for this machine.

The simulation and the experimental results have shown that additional eigenfrequencies and, hence, vibration modes appear in the spectrum according to different faults. The vibration modes, resulting from faults, inherently increase the noise of the machine. Moreover, vibration mode 1 is excited which causes a net radial force



Figure 19: Measured level of acceleration during runup - two faults (0101) at no load

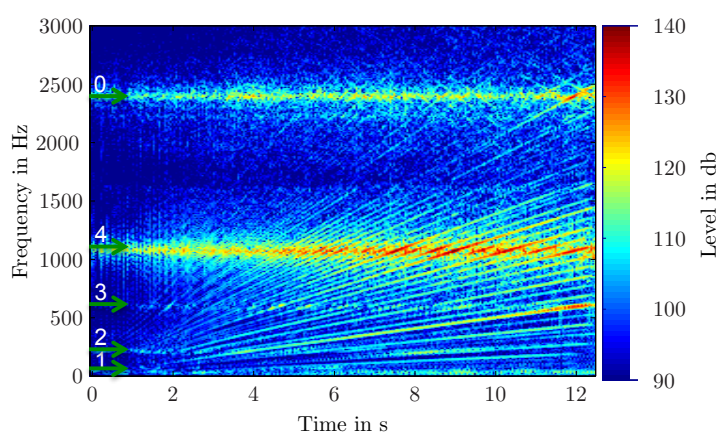

Figure 20: Measured level of acceleration during runup - failure of complete phase (0000) at no load

on the bearings. If one, two or three modules fail within one phase, mainly mode 1,2 and 3 are excited. In normal operation, only mode 0 and 4 are excited for the given five-phase 20/16 configuration of the SRM. The drawback of exciting mode 1,2 and 3 , is that the corresponding eigenfrequencies of these modes are all below $1000 \mathrm{~Hz}$. Therefore, a fault of a module leads to a significant increase in noise in a well audible frequency region. In particular, the excitation of mode 1 has to be avoided for two reasons: first, mode 1 causes the net radial force, which periodically stresses the bearings. Second, the eigenfrequency of mode 1 is $43 \mathrm{~Hz}$ for the analyzed prototype. This resonance is directly excited by the fundamental electric frequency at a common operating speed of $160 \mathrm{rpm}$.

Although the eigenfrequencies of mode 2 and 3 are higher than the maximum fundamental electric frequency, those modes are excited as well by multiples of the fundamental frequency, in the case of different faults. For instance, the fault of two opposite modules, leads to a significant excitation of mode 2 . Nevertheless, in case one module fails, turning off the opposite module prevents the excitation of modes 1 and 3 . However, it is advisable to turn off the complete phase if the application does not require maximum torque. Thereby, neither mode 1 nor mode 2 are excited. The remaining modules of the faulty phase should only be used if the maximum available torque with four phases needs to be increased.

The presented measurement results prove the concept of the distributed inverter, the proposed 
simulation model, the vibration analysis in case of different faults and the simple fault tolerant control strategy. The measured currents, torque and vibrations in case of different faults are in good agreement with the simulation results.

\section{Acknowledgments}

The authors would like to thank the German Research Foundation (DFG) (GZ DO 618/24-2) for financing this project.

\section{References}

[1] R. Quigley, "More electric aircraft," in Applied Power Electronics Conference and Exposition, 1993. APEC '93. Conference Proceedings 1993., Eighth Annual, Mar. 1993, pp. $906-911$.

[2] J. Rosero, J. Ortega, E. Aldabas, and L. Romeral, "Moving towards a more electric aircraft," Aerospace and Electronic Systems Magazine, IEEE, vol. 22, no. 3, pp. 3 -9 , march 2007.

[3] R. Krishnan, D. Blanding, A. Bhanot, A. Staley, and N. Lobo, "High reliability srm drive system for aerospace applications," in Industrial Electronics Society, 2003. IECON '03. The 29th Annual Conference of the IEEE, vol. 2, nov. 2003, pp. 1110 - 1115 Vol.2.

[4] S. MacMinn and W. Jones, "A very high speed switched-reluctance startergenerator for aircraft engine applications," in Aerospace and Electronics Conference, 1989. NAECON 1989., Proceedings of the IEEE 1989 National, May 1989, pp. 1758 -1764 vol.4.

[5] M. Hennen, M. Niessen, C. Heyers, H. Brauer, and R. De Doncker, "Development and control of an integrated and distributed inverter for a fault tolerant fivephase switched reluctance traction drive," Power Electronics, IEEE Transactions on, vol. PP, no. 99, p. 1, 2011.

[6] T. J. E. Miller, Switched reluctane motors and their control. Oxford University Press, ISBN 019859387 2, 1993.

[7] P. Lawrenson, J. Stephenson, N. Fulton, P. Blenkinsop, and J. Corda, "Variablespeed switched reluctance motors," Electric Power Applications, IEE Proceedings $B$, vol. 127 , no. 4 , pp. $253-265$, july 1980 .

[8] M. Krishnamurthy, B. Fahimi, and C. Edrington, "On the measurement of mutual inductance for a switched reluctance machine," in Power Electronics Specialists Conference, 2006. PESC '06. 37th IEEE, Jun. 2006, pp. $1-7$.
[9] L. Szabo and M. Ruba, "On fault tolerance increase of switched reluctance machines," in EUROCON 2009, EUROCON '09. IEEE, May 2009, pp. $734-739$.

[10] M. Ruba, C. Oprea, and L. Szabo, "Comparative study on switched reluctance machine based fault-tolerant electrical drive systems," in Electric Machines and Drives Conference, 2009. IEMDC '09. IEEE International, 3-6 2009, pp. 987 -992.

[11] M. Hennen, Switched Reluctance Direct Drive with Integrated Distributed Inverter, ser. Aachener Beiträge des ISEA, dissertation. Aachen: Shaker Verlag, ISBN 9783-8440-0731-2, February 2012, vol. 60.

[12] N. H. Fuengwarodsakul, Predictive PWMbased Direct Instantaneous Torque Control for Switched Reluctance Machines, ser. Aachener Beiträge des ISEA, dissertation. Aachen: Shaker Verlag, ISBN 978-3-83226210-5, May 2007, vol. 45.

[13] C. R. Neuhaus, N. H. Fuengwarodsakul, and R. W. De Doncker, "Predictive pwmbased direct instantaneous torque control of switched reluctance drives," in Power Electronics Specialists Conference, 2006. PESC '06. 37th IEEE, 2006, pp. 1-7.

[14] H. J. Brauer, M. D. Hennen, and R. W. De Doncker, "Multiphase torque-sharing concepts of predictive pwm-ditc for srm," in Power Electronics and Drive Systems, 2007. PEDS '07. 7th International Conference on, 2007, pp. 511-516.

[15] C. M. Stephens, "Fault detection and management system for fault-tolerant switched reluctance motor drives," IEEE Transactions on Industry Applications, vol. 27, no. 6, pp. 1098-1102, November 1991.

[16] V. K. Sharma, S. S. Murthy, and B. Singh, "Analysis of switched reluctance motor drive under fault conditions," in Industry Applications Conference, 1998. ThirtyThird IAS Annual Meeting. The 1998 IEEE, vol. 1, oct 1998, pp. 553-562.

[17] N. S. Gameiro and A. J. M. Cardoso, "Fault tolerant control strategy of SRM drives," in Power Electronics, Electrical Drives, Automation and Motion, 2008. SPEEDAM 2008. International Symposium on, jun 2008, pp. 301-306.

[18] M. Boesing, T. Schoenen, K. Kasper, and R. De Doncker, "Vibration synthesis for electrical machines based on force response superposition," Magnetics, IEEE Transactions on, vol. 46, no. 8, pp. $2986-2989$, Aug. 2010

[19] J. Fiedler, K. Kasper, and R. De Doncker, "Calculation of the acoustic noise spectrum of srm using modal superposition," Industrial Electronics, IEEE Transactions on, vol. 57, no. 9, pp. $2939-2945$, sept. 2010. 


\section{Authors}

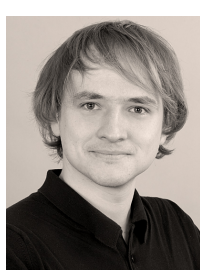

Martin D. Hennen was born in Saarburg, Germany in 1980. Starting in November 2005, he has been research associate at the Institute for Power Electronics and Electrical Drives in Aachen at RWTH Aachen University. In 2012 he received his Ph.D. degree in electrical engineering from the RWTH Aachen University. During his Ph.D. he has been working on design, control and fault tolerance of switched reluctance machines. Currently he is head of the office for electric mobility at RWTH Aachen University.

Matthias Boesing received the Diploma degree in electrical engineering from RWTH Aachen University, Aachen, Germany, in 2007. Since 2007, he has been a Research Associate with the Institute for Power Electronics and Electri-

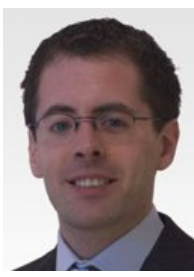
cal Drives (ISEA), RWTH Aachen University, where he is working on electric drives for electric and hybrid electric vehicles with respect to acoustic noise, control, and power electronics.
Rik W. De Doncker received the Ph.D. degree in electrical engineering from the Katholieke Universiteit Leuven, Leuven, Belgium, in 1986. In 1987, he was appointed Visiting Associate Professor at the University of Wisconsin, Madison. He was an Adjunct Researcher with IMEC, Leuven. In 1989, he joined the Corporate Research and Development Center, General Electric Company, Schenectady, NY. In 1994, he became the Vice President of Technology of Silicon Power Corporation (formerly GE-SPCO). He is currently a Professor at RWTH Aachen University, Aachen, Germany, where he leads the Institute for Power Electronics and Electrical Drives and, in 2006, became the Director of the E.ON Energy Research Cen-


ter. Dr. De Doncker was the President of the IEEE Power Electronics Society (PELS) in 2005 and 2006. He was the founding Chairman of the German IEEE IAS-PELS Joint Chapter. He was the recipient of the IAS Outstanding Achievement Award in 2002. 